\title{
Unilateral Diaphragm Paralysis Possibly Due to Cervical Spine Involvement in Multiple Myeloma
}

\author{
Murat Kara ${ }^{a}$ Metin Isik ${ }^{b}$ Levent Ozcakar ${ }^{a}$ Ozlem Erol ${ }^{a}$ Serkan Dogan ${ }^{b}$ \\ Kadrı Altundag ${ }^{c}$ Salih Aksu ${ }^{d}$ \\ Departments of a Physical Medicine and Rehabilitation, ${ }^{\mathrm{b}}$ Internal Medicine, ${ }^{\mathrm{c}}$ Medical Oncology and \\ ${ }^{\mathrm{d}}$ Hematology, Hacettepe University Medical School, Ankara, Turkey
}

\section{Key Words}

Multiple myeloma - Dyspnea · Diaphragm paralysis •

Back pain - Kyphoplasty

\begin{abstract}
Objective: To describe a patient with unilateral diaphragmatic paralysis due to multiple myeloma ( $\mathrm{MM}$ ) involving the cervical spine and related structures. Case Presentation and Intervention: A 52-year-old female presented with dyspnea, low back and widespread bone pain. She was diagnosed as having MM with vertebral involvement and unilateral paralysis of the diaphragm. She received two cycles of a chemotherapeutic regimen consisting of vincristine-Adriamycin-dexamethasone. The bisphosphonate zoledronic acid was also initiated at the same time. During follow-up, the back pain disappeared and the complaint of dyspnea decreased, although the paralysis persisted. Conclusion: As part of the differential diagnosis of bone and back pain, we draw attention to $\mathrm{MM}$ and the rare complication of diaphragmatic paralysis due to phrenic nerve involvement.
\end{abstract}

Copyright (c) 2006 S. Karger AG, Basel

\section{Introduction}

Multiple myeloma (MM) is a neoplastic disorder of plasma cells which accounts for $10 \%$ of all hematological cancers [1]. Vertebral involvement is quite common and MM patients are frequently admitted to the hospital with initial complaints of back pain. If MM is not included in the differential diagnosis, the underlying etiology for the back pain may be overlooked and the patient might undergo unnecessary interventions. In this report, we present an MM patient who had been operated upon for back pain and vertebral compressions in another hospital without a specific diagnosis of MM.

\section{Case Report}

A 52-year-old female was admitted with complaints of dyspnea, back and widespread bone pain and difficulty walking. Previously, she had been given alendronate and calcium supplements along with a low back exercise program. Subsequently, she was examined by a neurosurgeon who suggested surgery for the diagnosis of 'lumbar disk herniation'. She refused the operation and later was evaluated by several orthopedic surgeons. Eventually, she underwent surgery for the vertebral compressions using kyphoplasty. Unfortunately, no pathological diagnoses were available from surgical specimens. Her back pain did not subside after these treatments. A chest physician examined her for complaints of dyspnea. Labora-

\section{KARGER}

Fax +41613061234 E-Mail karger@karger.ch www.karger.com
Kadri Altundag, MD

8181 Fannin Street No. 728

Houston, TX 77054 (USA)

Tel. +1 713795 0438, Fax +1 7137944385

E-Mail altundag@sbcglobal.net 


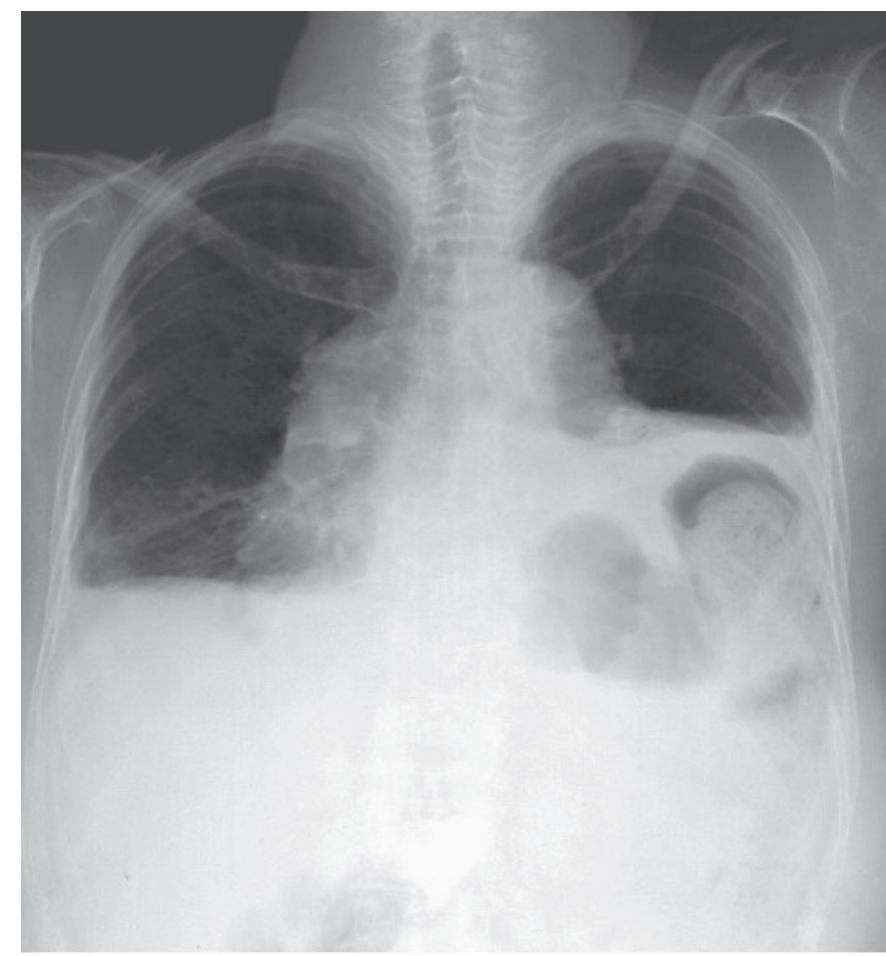

Fig. 1. The chest $X$-ray of the patient demonstrating the unilateral elevation of the diaphragm on the left side.

tory studies disclosed anemia and a decreased albumin/globulin ratio. These results together with her history of compression fractures resulted in the patient being referred to our hospital. The physical examination was consistent with malaise, palpitation, dyspnea, tachypnea and absence of pulmonary sounds in the left lower pulmonary lung fields.

The laboratory analysis revealed the following: hemoglobin, $11.1 \mathrm{~g} / \mathrm{dl}$ (normal 12-16); leukocyte count, 6,500/ $\mu \mathrm{l}(4,000-10,000)$; platelets, $250,000 / \mu \mathrm{l}(150,000-400,000)$; erythrocyte sedimentation rate, $74 \mathrm{~mm} / \mathrm{h}(0-20.0)$; creatinine, $1.0 \mathrm{mg} / \mathrm{dl}$; blood urea nitrogen, $30 \mathrm{mg} / \mathrm{dl}$ (4.6-23); total protein, $10.2 \mathrm{~g} / \mathrm{dl}$ (6.0-7.8); albu$\mathrm{min}, 3.2 \mathrm{~g} / \mathrm{dl}$ (3.2-4.8); globulin, $7.00 \mathrm{~g} / \mathrm{dl}$ (1.5-4.6); $\beta_{2}$-microglobulin, $4.34(0.9-2.0)$. Serum protein electrophoresis yielded: $\gamma$-globulin, 48.8\% (oligoclonal peak); albumin, 30.7\%; $\alpha_{1}, 5.6 \% ; \alpha_{2}$, $9.2 \%$; $\beta$-globulin, $5.7 \%$. Using immune-fixed electrophoresis, oligoclonal $\lambda$ light chains were observed in urinalysis. A chest X-ray depicted a left-sided elevation of the diaphragm (fig. 1). Computed tomography of the thorax revealed an elevation of the diaphragm on the left side with decreased lung volume. During fluoroscopy the left diaphragm was elevated and motionless throughout the respiration cycles. The tidal volume was $460 \mathrm{~cm}^{3}$. Skeletal survey revealed multiple lytic lesions in the skull, ribs, pelvis, humerus and both femurs with generalized osteopenia. The cervicothoracolumbar magnetic resonance imaging demonstrated diffuse vertebral involvement and multiple compressions, predominantly of the cervical vertebrae (fig. $2 \mathrm{a}, \mathrm{b}$ ). Bone marrow biopsy revealed abnormal plasma cell infiltration. As a result, the patient was diagnosed as having MM with generalized bony involvement and left-sided dia-
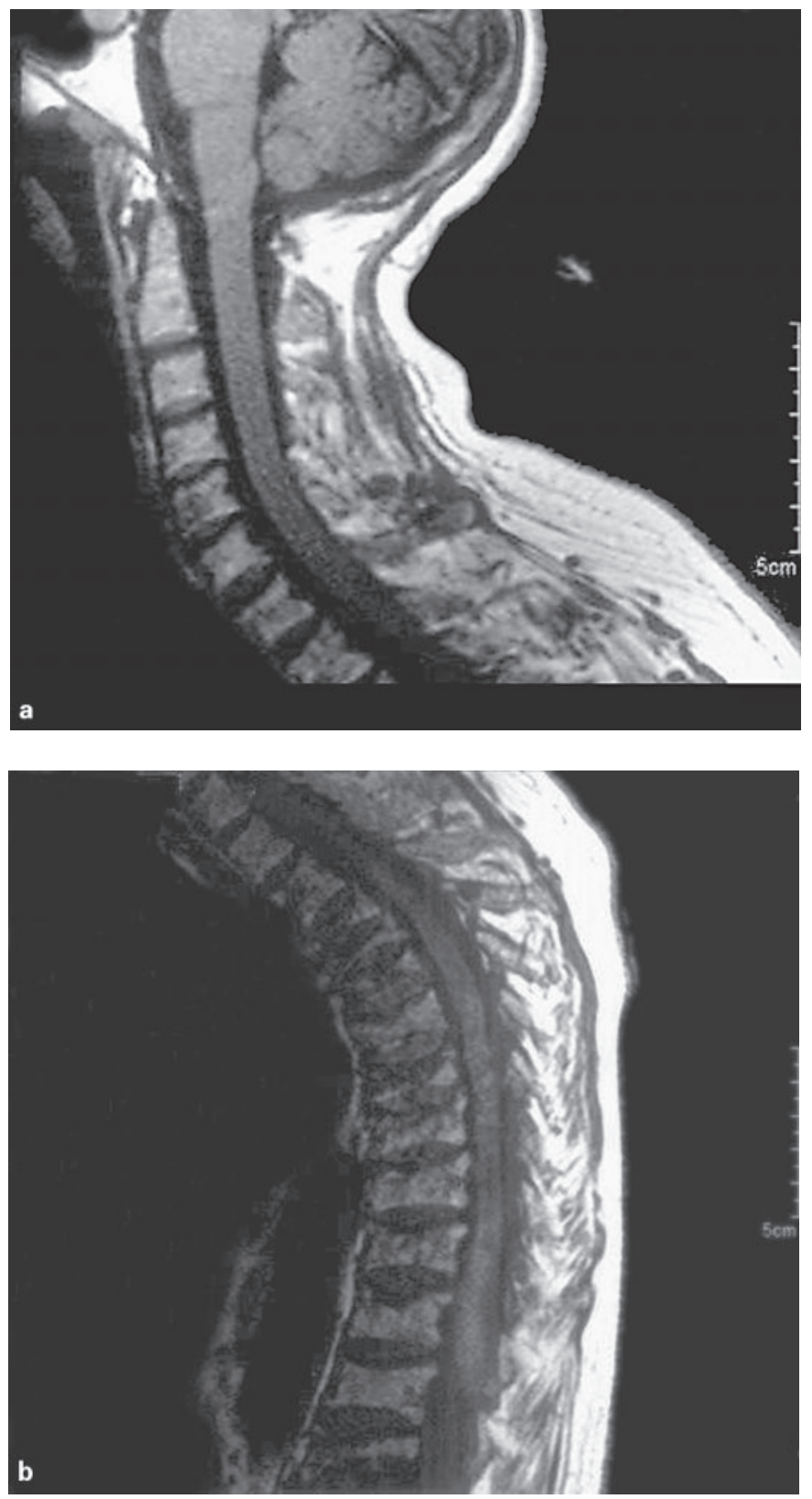

Fig. 2. a Magnetic resonance imaging $T_{1}$-weighted sagittal view of the cervical vertebrae depicting the extensive lytic lesions and several compressions. $\mathbf{b} \mathrm{T}_{1}$-weighted sagittal view of the thoracal vertebrae depicting the extensive lytic lesions and several compressions.

phragmatic paralysis due to cervical cord and/or nerve compression.

The patient received two cycles of a chemotherapeutic regimen consisting of vincristine-Adriamycin-dexamethasone. The bisphosphonate zoledronic acid, $4 \mathrm{mg}$ i.v. every 28 days, was also initiated. During the follow-up, the back pain resolved and the complaint of dyspnea decreased although the paralysis persisted. 


\section{Discussion}

$\mathrm{MM}$ is a hematological malignancy with abnormal monoclonal plasma cell proliferation, skeletal destruction, renal failure, anemia and hypercalcemia. The most common symptoms on presentation are fatigue, bone pain and recurrent infections. Patients who are eligible for autologous stem cell transplantation are first treated with a regimen that is not toxic to hematopoietic stem cells. Those who are not eligible for transplantation because of age, poor physical condition or coexisting conditions receive standard therapy with alkylating agents. Recent promising advances in the treatment of MM include the use of thalidomide and new drugs such as bortezomib and CC-5013 [2]. Moreover, bisphosphonates, namely zoledronic acid and pamidronate, have a widely recognized antiosteoclastic activity that decreases skeletal destruction by $50 \%$ in advanced MM [3].

Abnormal plasma cells proliferate in the bone marrow and then invade the bone causing lytic lesions [4]. The lytic lesions, osteoporosis and subsequent pathological fractures are present in $75 \%$ of patients [5]. They are often responsible for the complaints of various types of bone pain which exist in two thirds of the patients at the time of diagnosis [6]. Involvement of the vertebrae may result in compression fractures and vertebral collapse [7]. Besides causing back pain, these complications may frequently cause compression of the spinal cord or the spinal nerves [7-9]. Otherwise, peripheral neuropathies are an uncommon finding in MM. If present, these neuropathies result from immunoglobulins reacting against myelin-associated glycoproteins and peripheral nerve antigens or to amyloid deposition [5]. Other neurological symptoms of MM include headache, blurring of vision, precomacoma, vertigo, ataxia, seizures and paraplegia [10]. Similarly, cranial nerves II, V, VI, VII, VIII may also be involved [11]. To the best of our knowledge, unilateral phrenic nerve involvement in MM has not been reported in the literature. In this patient, the left phrenic nerve might have been injured due to the involvement of MM in the cervical vertebrae, resulting in compression of the cervical roots forming the left phrenic nerve. Unfortunately, phrenic nerve conduction studies, diaphragmatic electromyography and imaging to visualize structural damage to the ventral roots comprising the phrenic nerves were not done. However, since our patient had no accompanying neurological complaints, an infiltrative cause or immunological reaction leading to polyneuropathy was considered unlikely. Other causes of unilateral diaphragmatic paralysis include tumors, more commonly bronchogenic lung cancer, postsurgical complications, neurological disorders (myelitis, encephalitis, poliomyelitis and herpes zoster) [12], but these were ruled out in our patient. A plication operation for the diaphragm was not recommended for our patient since her dyspnea resolved after chemotherapy and her tidal volume was $460 \mathrm{~cm}^{3}$.

\section{Conclusion}

This case shows that phrenic nerve paralysis from cervical vertebral compression may be an unusual complication of MM. Additionally, it is important to include MM in the differential diagnosis of back or generalized bone pain, which will facilitate the proper diagnosis and prompt treatment of this disease.

\section{References}

-1 Rajkumar SV, Gertz MA, Kyle RA, Greipp PR; Mayo Clinic Myeloma, Amyloid and Dysproteinemia group: Current therapy for multiple myeloma. Mayo Clin Proc 2002;77:813822.

$>2$ Kyle AR, Rajkumar SV: Multiple myeloma. N Engl J Med 2004;351:1860-1873.

3 Bruno B, Rotta M, Giaccone L, et al: New drugs for treatment of multiple myeloma. Lancet Oncol 2004;5:430-442.

4 Ashcroft AJ, Davies FE, Morgan GJ: Aetiology of bone disease and the role of bisphosphonates in multiple myeloma. Lancet Oncol 2003; 4: 284-292.
5 Kyle RA: Multiple myeloma; in Goldman L, Dennis A (eds): Cecil Textbook of Medicine. Philadelphia, Saunders, 2000, pp 980-982.

-6 Kanis JA, McCloskey EV: Bisphosphonates in multiple myeloma. Cancer 2000;88(suppl); 3022-3032.

7 Dudeney S, Hussein M, Lieberman IH: Kyphoplasty in the treatment of vertebral fractures secondary to multiple myeloma. Spine J 2002;2(suppl 1):18-19.

$>8$ Roodman GD: Mechanisms of bone lesions in multiple myeloma and lymphoma. Cancer 1997;80:1557-1563.

-9 Mundy GR, Bertolini DR: Bone destruction and hypercalcemia in plasma cell myeloma. Semin Oncol 1986;13:291-299.
10 Pizzuti P, Pertuiset E, Chaumonnot F, Chesneau A, Mikol J, Leblond-Missenard V, Fermand JP: Neuromeningeal sites of multiple myeloma: 3 cases and review of the literature. Rev Méd Interne 1997;18:646-651.

11 Basic-Kes V, Basic-Jukic N, Kes P, Demarin V, Labar B: Neurologic sequelae of bone changes in multiple myeloma and its therapy. Acta Med Croat 2002;56:103-107.

$\checkmark 12$ Higgs SM, Hussain A, Jackson M, Donnelly RJ, Berrisford RG: Long term results of diaphragmatic plication for unilateral diaphragm paralysis. Eur J Cardiothorac Surg 2002;21: 294-297. 